\title{
Verb Aspect and the Activation of Event Knowledge
}

\author{
Todd R. Ferretti \\ Wilfrid Laurier University
}

\author{
Marta Kutas \\ University of California, San Diego
}

\author{
Ken McRae \\ University of Western Ontario
}

\begin{abstract}
The authors show that verb aspect influences the activation of event knowledge with 4 novel results. First, common locations of events (e.g., arena) are primed following verbs with imperfective aspect (e.g., was skating) but not verbs with perfect aspect (e.g., had skated). Second, people generate more locative prepositional phrases as completions to sentence fragments with imperfective than those with perfect aspect. Third, the amplitude of the N400 component to location nouns varies as a function of aspect and typicality, being smallest for imperfective sentences with highly expected locations and largest for imperfective sentences with less expected locations. Fourth, the amplitude of a sustained frontal negativity spanning prepositional phrases is larger following perfect than following imperfective aspect. Taken together, these findings suggest a dynamic interplay between event knowledge and the linguistic stream.
\end{abstract}

Keywords: verb aspect, event knowledge, semantic priming, sentence processing, ERP

On many accounts, the information extracted at a verb serves to activate knowledge of the various roles associated with the action denoted by the verb, as well as structural knowledge regarding how those roles may be expressed. Verbs in general, and their morphologies in particular, also play important roles in theories of sentence processing (MacDonald, Pearlmutter, \& Seidenberg, 1994; Trueswell, Tanenhaus, \& Garnsey, 1994). Several recent studies have demonstrated that verbs are an important source of information about people's conceptual knowledge concerning specific events, including typical participants, instruments, time course, and duration. Moreover, these studies have provided evidence that such information is available quickly for online use during sentence processing (Altmann \& Kamide, 1999; Ferretti, McRae, \& Hatherell, 2001; McRae, Ferretti, \& Amyote, 1997; McRae, Spivey-Knowlton, \& Tanenhaus, 1998). The activation of this conceptual information also has been found to be influenced

Todd R. Ferretti, Department of Psychology, Wilfrid Laurier University, Waterloo, Ontario, Canada; Marta Kutas, Department of Cognitive Science, University of California, San Diego; and Ken McRae, Department of Psychology, University of Western Ontario, London, Ontario, Canada.

This research was supported by National Sciences and Engineering Research Council of Canada (NSERC) Discovery Grant 261759 and Canadian Foundation for Innovation Grant 9433 awarded to Todd R. Ferretti, by National Institute of Child Health and Human Development Grant HD22614 and National Institute of Aging Grant AG08313 to Martha Kutas, and by NSERC Grant OGP0155704 and National Institutes of Health Grant MH6051701 to Ken McRae. Marta Kutas was a Lady Davis Fellow at Hebrew University, Jerusalem, Israel, during the writing of the manuscript.

Correspondence concerning this article should be addressed to Todd R. Ferretti, Centre for Cognitive Neuroscience, Department of Psychology, Wilfrid Laurier University, 75 University Avenue, Waterloo, Ontario, Canada N2L 3C5. E-mail: tferrett@wlu.ca by the inflectional morphology of verbs and participles that signal voice, tense, and aspect (Ferretti, Gagné, \& McRae, 2003; Ferretti et al., 2001; Madden \& Zwaan, 2003; Magliano \& Schleich, 2000). In the present research, we extend these findings by showing how verb aspect influences the activation of event knowledge when people read verb phrases appearing either in isolation or within single sentences.

\section{Verb Aspect and Language Processing}

The grammatical category of aspect captures some ways in which language uses morphology to refer to the temporal structure of events (e.g., ongoing versus completed). In this article, we contrast imperfective and perfect aspect. Imperfective aspect makes specific reference to the internal structure of events by focusing on their ongoing development (see Figure 1), but makes no reference to their completion. The imperfective category is frequently subdivided by linguists into progressive and habitual categories. The English progressive is marked with the verbal form be -ing (e.g., is scoring, was scoring, will be scoring) and focuses on the internal phases of dynamic events (Comrie, 1976; Langacker, 1982; Smith, 1991). Perfect aspect is used to refer to some time period that follows the event, and it places emphasis on the resultant phases (or states) rather than on inceptive phases (Comrie, 1976). In English, this aspectual category is marked by to have + past participle (e.g., has scored, had scored, will have scored). In general, perfect aspect functions to indicate the continuing relevance of a past situation for the present or for some other reference time (Comrie, 1976).

To understand why verb aspect may play a crucial role in modulating event knowledge, one must consider both the causal and the temporal structure of events because they are closely intertwined (see Figure 1). For example, the temporal structure of events can be decomposed into three general components. 


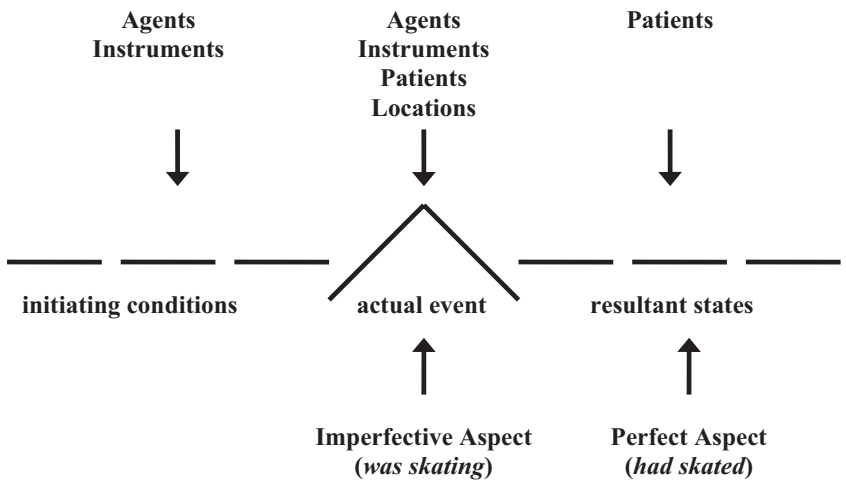

Figure 1. Verb aspect, thematic roles, and their general relationship with the temporal and causal structure of events.

According to Moens and Steedman (1988), these temporal components correspond closely to the causal properties of events, which include initiating conditions (beginning), the actual event (middle), and the resultant states (end). Related to these causal components are the entities, objects, and locations that typically are part of events. It is important to note that the entities and objects in events will be more or less salient during the different causal components. As illustrated in Figure 1, agents typically are associated with the initiating conditions of an event because they tend to cause them to occur. In contrast, patients are typically associated with the resultant states of an event because they typically undergo a change of state as a result of the action performed by some agent. Instruments tend to be part of the initiating conditions because they are often used by some agent to perform some action. Location and instrument information is often salient during ongoing events but not after they are completed. We propose that the temporal reference of verb aspect for events should function to enhance activation of event knowledge for the thematic roles that are consistent with the temporal reference of the different aspect categories (i.e., ongoing vs. completed events). Most relevant for the present research, location information should be most salient for events that are linguistically signaled as ongoing.

The temporal and causal properties of events and verb aspect have been shown to interact to influence the activation and construction of situation models during language comprehension. Verb aspect seems to play two important roles in this regard. First, these two aspectual categories differentially foreground and background information pertaining to events (Carreiras, Carriedo, Alonso, \& Fernandez, 1997; Givón, 1992; Hopper, 1982; Madden \& Zwaan, 2003; Magliano \& Schleich, 2000; Morrow, 1985, 1990). Carreiras et al. (1997) and Magliano and Schleich (2000) demonstrated that imperfective aspect influences the activation of events and their corresponding participants in a comprehender's mental model of the text, whereas the events were not as available when marked with perfect and perfective aspect. Second, aspect has been found to influence the activation of world knowledge about common properties associated with events (Madden \& Zwaan, 2003; Magliano \& Schleich, 2000; Truitt \& Zwaan, 1997). For example, Truitt and Zwaan (1997) found that the word hammer (an instrument) was primed more strongly after the sentence He was pounding the nail than after He pounded the nail.
In the current research, we investigate how verb aspect influences the activation of world knowledge about locations where common events typically occur. Evidence that verb aspect interacts with location information has been provided in a series of studies by Morrow and colleagues (Morrow, 1985, 1990). Morrow (1990) asked participants to memorize the layout of a house given a floor plan illustrating the location of a kitchen, bathroom, living room, and hallway. Subsequently, they were asked to read sentences such as (1a) and (1b) and to indicate where they thought the figure (e.g., John) was located within the house at the time described by the sentence:

(1a) John was walking from the kitchen to the bedroom.

(1b) John walked from the kitchen to the bedroom

Morrow found that when the imperfective aspect was used (as in 1a), readers were more likely to locate the figure somewhere between the kitchen and the bedroom. By contrast, when the verbs were in their perfective form (1b), readers reliably located the figure at or inside the goal (bedroom). Readers thus used the combination of aspect and the information provided by prepositions to infer the location of the figure in a spatially organized mental model. These results shed light on how comprehenders use aspect to make salient various components of events, including the locations of the entities involved in the event.

In the present research, we used both behavioral and electrophysiological measures to examine whether verb aspect influences the activation of world knowledge about location information from verbs presented in isolation as well as in sentence contexts. Thus, our goal is to gain insight into how verb aspect influences language comprehension. Experiment 1 extends previous research by probing for activation of location information immediately after verb phrases. Experiment 2 examines how verb aspect influences people's expectations for types of postverbal phrases in a sentencecompletion task. Experiment 3 uses event-related brain potential (ERP) methodology to examine how verb aspect influences the online comprehension of sentences with locative prepositional phrases.

\section{Experiment 1}

Using animacy and lexical decision paradigms, Ferretti et al. (2001) found priming from verbs to instruments (dug-spade), agents (arresting-cop), and patients (arresting-criminal) but not locations (skated-arena). One possible explanation for the lack of location priming is that locations tend to be background information for most situations and thus may not be as salient in the causal structure of events as are agents, patients, and instruments. The research reviewed above, however, indicates that backgrounded information about situations can be foregrounded with imperfective aspect (Carreiras et al., 1997). Furthermore, as shown by Morrow (1985, 1990), imperfective aspect highlights the path along which figures are moving. Taken together, these results suggest that Ferretti et al. may not have obtained priming for locations because the verb primes were not presented in their imperfective form. If this hypothesis is correct, then the common locations for the situations denoted by their verbs will be activated (primed) to a greater degree if the same verbs are marked with 
imperfective aspect. ${ }^{1}$ We tested this hypothesis using a short stimulus onset asynchrony (SOA; the time between the onsets of the prime and the target) semantic priming task with a subset of the verb-location pairs used in Ferretti et al. (2001). Note that our prediction is derived from a perspective in which the temporal properties of events are computed quickly and have a rapid impact on processing. In contrast, this prediction does not follow from a spreading activation account because aspectual properties play no role (Collins \& Loftus, 1975; Rumelhart \& Levin, 1975). We return to this point in the Discussion.

\section{Method}

\section{Participants}

Forty-eight undergraduates participated for course credit. All were native-English-speaking psychology undergraduates from the University of California, San Diego, who had normal or corrected-to-normal visual acuity.

\section{Materials}

Twenty-four verb-location pairs were chosen on the basis of a norming study reported in Ferretti et al. (2001). Forty participants rated how typical a specific location is for the event denoted by a verb. Participants provided ratings on a scale from 1 (very uncommon) to 7 (very common) for questions such as "How common is it for someone to skate in each of the following locations?" The verb-location pairs and their ratings are presented in Appendix A.

Participants were randomly assigned to one of four lists, each containing 24 verb-location items. Each list contained 6 related past imperfective pairs (e.g., was skating-arena), 6 unrelated past imperfective pairs (was praying-arena), 6 related past perfect pairs (had skated-arena), and 6 unrelated past perfect pairs (had prayed-arena). The unrelated trials were formed by re-pairing the related verb-noun combinations, although there were four exceptions. The related and unrelated verb-location pairings used in the current study were identical to those used in Ferretti et al. (2001). In that study, we also examined verb-instrument pairs that included four verbs that overlapped with the verb-location pairs (fished, hunted, gambled, ate). Therefore, in Ferretti et al. (2001), to ensure that no participant saw any verb more than once, we replaced the four overlapping verbs with semantically similar verbs (trawled, tracked, bet, devoured). To allow for direct comparison between the present Experiment 1 and Ferretti et al. (2001), we also used these four semantically similar verbs in the unrelated condition in the current experiment. Therefore, each target noun served as its own control, and no participant saw any word more than once. The four lists included the same set of 48 filler trials composed of unrelated verb-noun pairs. Half of the filler trials were composed of verbs marked with imperfective aspect, and the other half were marked with perfect aspect. The relatedness proportion was .17 (12/72). Finally, 12 practice trials were constructed that included 6 verbs marked with imperfective aspect and 6 verbs marked with perfect aspect.

\section{Procedure}

Stimuli were displayed on a 14-in. Sony Trinitron monitor controlled by a Macintosh LC630 using PsyScope (Cohen, MacWhinney, Flatt, \& Provost, 1993). The priming paradigm used was a short-SOA pronunciation task. Each trial consisted of the following events: a focal point $(+)$ in the center of the screen for $250 \mathrm{~ms}$; the prime (was skating) for $250 \mathrm{~ms}$; and then the target (arena) until the participant named the target noun. The intertrial interval was $1,500 \mathrm{~ms}$. Participants were instructed to read the verb phrase silently and to name the noun aloud into the microphone as quickly and accurately as possible. Latencies were recorded with millisec- ond accuracy via a microphone attached to a Carnegie Mellon University button box that measured the time between the onset of presentation of the target word and onset of the naming response. Testing sessions began with the practice trials. This task took approximately 20 min to complete.

\section{Results}

Three-way analyses of variance were conducted using naming latency as the dependent variable. The two independent variables of interest were relatedness (related vs. unrelated) and aspect (imperfective vs. perfect). Aspect and relatedness were within participants $\left(F_{1}\right)$ and within items $\left(F_{2}\right)$. Planned comparisons were conducted to investigate priming effects for both forms of aspect. In all analyses reported in this article, list $\left(F_{1}\right)$ was used as a between-participants factor and item rotation group $\left(F_{2}\right)$ as a between-items factor to stabilize any variance caused by rotating items and participants across the different lists (Pollatsek \& Well, 1995). Effects involving these variables are not reported.

Mean naming latencies by condition are presented in Table 1. A trial was excluded from the latency analyses if the response was incorrect. Because pronunciation errors occurred on less than $1 \%$ of the trials, they were not analyzed further. In addition, less than $1 \%$ of the trials were discarded because of extraneous noise or failure to trigger the microphone. Finally, response latencies greater than three standard deviations above the grand mean were replaced by that value (less than $1 \%$ of the scores).

Aspect and relatedness interacted, $F_{1}(1,44)=4.95, p<.05$; $F_{2}(1,20)=7.60, p<.02$. This interaction reflects a $21-\mathrm{ms}$ priming effect for locations when verbs were marked with imperfective aspect, $F_{1}(1,44)=7.41, p<.01 ; F_{2}(1,20)=16.46, p<$ .01 , but no priming effect when the verbs were marked with perfect aspect ( $F<1$ in both analyses). Collapsed across relatedness, naming latencies were significantly shorter for imperfective $(M=600 \mathrm{~ms}, S E=10 \mathrm{~ms})$ than for perfect trials $(M=612 \mathrm{~ms}$, $S E=11 \mathrm{~ms}), F_{1}(1,44)=6.68, p<.02 ; F_{2}(1,20)=4.55, p<$ .05 . Overall, naming latencies for related items $(M=602 \mathrm{~ms}$, $S E=11 \mathrm{~ms}$ ) were numerically shorter than for unrelated items ( $M=611 \mathrm{~ms}, S E=10 \mathrm{~ms}$ ), but as a result of the form of the interaction, the main effect of relatedness was nonsignificant, $F_{1}(1$, $44)=1.82, p>.18 ; F_{2}(1,20)=3.06, p<.10$.

\section{Discussion}

Experiment 1 extends previous research by showing that aspect modulates activation of world knowledge of common locations at which events occur. Specifically, participants named locations more quickly when they were preceded by verbs denoting an event for which the locations were typical than when they were preceded by unrelated verbs, but only when the verbs were marked with imperfective aspect. From an event structure perspective, the probability of an individual staying at the same location after an event is difficult to determine. For example, if someone had finished swimming, they might still be at the ocean, or they could be

\footnotetext{
${ }^{1}$ We note that this prediction is based on the assumption that location information is not usually crucial to the outcomes or results of actions However, in other cases, the locations may be more focused for completed events, especially in cases in which the locations are the goal of particular actions (e.g., climb)
} 
Table 1

Mean Naming Latencies (ms) in Experiment 1

\begin{tabular}{lccccc}
\hline & \multicolumn{2}{c}{ Imperfective } & & \multicolumn{2}{c}{ Perfect } \\
\cline { 2 - 3 } \cline { 5 - 6 } Word & $M$ & & & $M$ & $S E$ \\
\hline Uairing & 611 & 14 & & 611 & 15 \\
Unrelated & 590 & 14 & & 614 & 16 \\
Related & $21^{*}$ & & & -3 & \\
Facilitation & & & &
\end{tabular}

Note. Asterisk signifies significant by participants and items.

driving home or eating in a restaurant. Furthermore, as illustrated in Figure 1, location information is in general less likely to have continuing relevance in the resultant states of events because it is normally not as strongly associated with the causal structure as the entities that interact in those events. The results are thus consistent with previous research showing that the imperfective aspect highlights the path or location of entities in events (Morrow, 1990). Finally, these results are also consistent with Ferretti et al. (2001), suggesting that they did not obtain priming for typical locations because their past tense verbs referenced events as completed rather than as ongoing.

\section{Implications for the Semantic Priming Literature}

To the best of our knowledge, this is the first time that verbs with aspectual morphemes have been used as primes in a shortSOA priming task. It is thus important to consider the implications of these results for accounts of semantic priming. The most common explanation of word-word priming results is based on the notion of spreading activation (see Neely, 1991, for an extensive review). The original instantiations of semantic networks focused on noun representations (Collins \& Loftus, 1975; Collins \& Quillian, 1969). Subsequent extensions incorporated verb meaning into such frameworks (Gentner, 1975; Rumelhart \& Levin, 1975). A verb's representation in Gentner's (1975) and Rumelhart and Levin's (1975) models included core meaning and thematic links to nodes that stood as placeholders for various thematic roles. However, it is important to note that these thematic links and nodes included minimal semantic content. Rumelhart and Levin, for example, assumed that the agent link carried with it only the information that whatever noun could be placed in that node must be animate. In other words, semantic content was restricted to general selectional restriction information. Because all locations in our materials are equivalent in terms of selectional restrictions, in their current instantiations, these models cannot account for the priming effects obtained in Experiment 1.

Current semantic networks (including, e.g., Nelson, McEvoy, \& Pointer, 2003) could be extended so that over time, a verb node becomes linked to noun nodes representing its common locations as a result of experience with situations to which the verb refers, and linguistic descriptions of them. These links could result from people noticing that, for example, arenas are associated with skating, or via word co-occurrence in speech and text. If all words or concepts that tend to co-occur frequently in situations are linked in semantics and/or orthography and phonology via an associative relation, then priming from verbs to typical role fillers could result. Note that the standard offline method for determining whether two words or concepts share an associative link is word-association norms. It has been argued that if participants frequently produce one word given another in a word-association task, then those concepts share an associative link, and facilitation should obtain in an online priming task (Neely, 1991). However, this type of explanation cannot account for the present results, as none of the items was associated according to word-association norms. ${ }^{2}$

Even more problematic for spreading activation theory, however, is how to explain the modulation of location priming by grammatical morphemes. In present versions of spreading activation networks, there do not exist, for example, separate nodes for verbs in different tenses, let alone for verbs used with different aspectual markers. If verbs were connected through undifferentiated links to their typical locations, one would expect priming regardless of aspectual marking. Our finding that location information was primed only with imperfective aspect suggests that the spread of activation in semantic memory must be modified so as to allow it to be constrained by syntactic information such as grammatical inflections on verbs. Of course, spreading activation networks could incorporate ad hoc assumptions based on the temporal characteristics of events, but these are outside the scope of extant models. The results of Experiment 1 are, however, consistent with Ferretti et al.'s (2001) claim that human memory is functionally organized so that when a verb is read or heard, situation-specific information is made available immediately via a situation schema.

\section{Experiment 2}

We investigated people's postverbal phrase preferences following verbs that vary in aspectual form. We used a sentencecompletion task to examine the kind of information that people feel is natural to follow specific subject-verb combinations (e.g., The cow was grazing, The cow had grazed ...). On the basis of Experiment 1, we predicted that if location information is more strongly activated after reading ongoing versus completed events, then people should be more likely to complete sentences with locative prepositional phrases when the events are presented as ongoing. Conversely, if referencing an event as completed focuses the reader on the resulting states or outcomes of events, then we expect the participants and objects that are causally influenced by a sentence's subject to be more in focus than locations. Thus, we expect participants and objects to appear in more postverbal noun phrases for events referenced as completed than for events referenced as ongoing.

The second goal of Experiment 2 was to use the sentence completions as a measure of verb phrase preference for the verbs used in the online reading task presented in Experiment 3. That is, we used the sentence completions to estimate the frequency with which each subject-verb combination is likely to be followed by different types of phrases (noun phrases, prepositional phrases, adverbial phrases, conjunctive phrases, etc.). This information can

\footnotetext{
2 The word-association norms are reported in Ferretti et al. (2001). Participants were read the verbs and asked to produce the first word that came to mind. A verb-noun pair was considered associated if the noun was produced to the verb by greater than $5 \%$ of the participants, which is a conservative criterion when compared with other priming experiments that have aimed to eliminate associatively related items from their stimuli (Moss, Ostrin, Tyler, \& Marslen-Wilson, 1995; Shelton \& Martin, 1992).
} 
in turn be used to examine how verb phrase preferences influence online language comprehension. An alternative methodology for estimating postverbal preferences is to examine the frequency of the types of phrases that follow specific verbs in a large language corpora. However, the number of instances in which our specific subject-verb combinations appear in different corpora would often be so low that it would be difficult, if not impossible, to get an accurate estimation of postverbal preferences for these items, particularly when aspect is taken into account. For example, a Google search of English Web pages on the Internet (presumably one of, if not the largest, language corpora available) for sailor was napping and sailor had napped did not yield any hits for the imperfective or perfect form of those subject-verb combinations.

\section{Method}

\section{Participants}

Eighty native-English-speaking psychology undergraduates from the University of California, San Diego, who had normal or corrected-tonormal visual acuity participated for course credit.

\section{Materials and Procedure}

We created 112 subject-verb combinations that involve events in which entities tend to perform actions in a narrow range of locations. These combinations were preceded by a determiner to complete the sentence fragments used in the completion task (as in $2 \mathrm{a}$ and $2 \mathrm{~b}$ ).

(2a) The diver was snorkeling

(2b) The cow had grazed

Two booklets were created that contained 112 sentence fragments. The sentence fragments were rotated through the booklets so that no fragment appeared more than once in each booklet, and each booklet had an equal number of sentence fragments with past imperfective and past perfect aspect. That is, if The cow was grazing appeared in one booklet, then The cow had grazed appeared in the other, so that each booklet contained half of the sentence fragments with imperfective aspect and the opposing half with past perfect. Two additional booklets were created that were identical to the first two except that the items appeared in reversed order.

Participants were given one booklet and were provided with the following instructions: "For each of the following, please write a continuation that you feel makes the sentence sound the most natural." Each booklet took approximately $45 \mathrm{~min}$ to complete.

\section{Results}

The sentence completions $(N=8,960)$ were coded for the type of phrase that immediately followed the verbs. Noun phrases, prepositional phrases, adverbial phrases, and conjunctive phrases constituted $99 \%$ of the completions. The other $1 \%$ consisted of a variety of infrequent phrases, phrases that were incomplete continuations, or phrases that were not grammatical. As a result of the infrequent occurrence of "other" completions, these were removed from the analyses, and the proportions of noun, preposition, adverb, and conjunctive phrases were normalized. Finally, because we were interested in the frequency of locative prepositional phrases that were provided as completions, and not just overall prepositional phrase frequency, we also coded the prepositional phrases for whether they were locative or other prepositional phrases. The "other prepositional phrase" category consisted mainly of temporal (e.g., in the evening) and manner phrases (e.g., in a hurry). The normalized values are presented in Table 2.

One-way analyses of variance were conducted for each type of phrase using proportion of completions as the dependent variable. The main factor of interest was aspect (imperfective vs. perfect), which was within items $\left(F_{2}\right) .^{3}$

\section{Prepositional Phrase Completions}

Overall, people completed the sentence fragments significantly more often with prepositional phrases when the verbs were in past imperfective (51\% of completions) versus past perfect form (42\% of completions), $F_{2}(1,110)=32.01, p<.001$. Our primary interest with prepositional phrase completions was the proportion of locative prepositional phrases following verbs marked with the two forms of aspect. Consistent with our predictions, participants completed the sentence fragments significantly more often with locative prepositional phrases when the verbs were in their imperfective (37\% of completions) versus perfect form (28\% of completions), $F_{2}(1,110)=35.20, p<.001$. The $9 \%$ difference between the two aspectual categories for locative prepositional completions accounts for the overall difference in prepositional phrase completions.

\section{Other Completions}

Participants completed the sentence fragments more often with noun phrases when the verbs were in their perfect (43\% of completions) versus imperfective forms (38\% of completions), $F_{2}(1$, $110)=16.87, p<.001$. This result is consistent with the prediction that the perfect aspect focuses on the entities and objects that are associated with the resultant states of events. Adverbial completions (The tiger was roaring loudly) were more frequent when the verbs were in perfect (12\% of completions) versus imperfective form (9\% of completions), $F_{2}(1,110)=13.18, p<.001$. Finally, conjunctive phrases (The woman was swimming and she hurt herself) were provided equally often with imperfective ( $2 \%$ of completions) and perfect aspect (3\% of completions) $\left(F_{2}<1\right)$.

\section{Discussion}

Verb aspect influences the types of information that participants tend to produce following those verbs in an offline task. Participants were more likely to complete sentences with locative prepositional phrases when events were referenced as ongoing with past imperfective aspect. In contrast, when the events were referenced as completed, participants were more likely to refer to some entity or object in noun phrases and were more likely to modify the event with adverbial information primarily denoting time (swam for 4 hours) and manner (sung loudly). These results are consistent

\footnotetext{
${ }^{3}$ We present only items analyses in Experiment 2, because our initial encoding of these norms did not permit an analysis by subjects. In Experiment 3, we also present only an item analysis for the results of the $t$ test that contrasted the scores for the locations in the high- and low-expectancy conditions. In this case, only item analysis could have been conducted as a result of the nature of how we calculated the expectancy scores for each noun (i.e., by noting the frequency and rank order in which participants provided the locations).
} 
Table 2

Percentage of Verb Phrase Preferences for Verbs Marked With Imperfective and Perfect Aspect in Experiment 2

\begin{tabular}{lrrrrrr}
\hline & \multicolumn{2}{c}{ Imperfective } & & \multicolumn{2}{c}{ Perfect } & \\
\cline { 2 - 3 } \multicolumn{1}{c}{ Phrase type } & $M$ & $S E$ & & $M$ & $S E$ & Difference \\
\hline Preposition (other) & 13 & 2 & & 14 & 2 & -1 \\
Preposition (locative) & 37 & 3 & & 28 & 3 & 9 \\
Noun & 38 & 4 & & 43 & 4 & -5 \\
Adverb & 9 & 1 & & 12 & 1 & -3 \\
Conjunction & 2 & 0.4 & 3 & 0.5 & -1 \\
\hline
\end{tabular}

with the notion that event location information is more highly activated, salient, and/or natural when events are presented as unfolding in time, at least for events that tend to occur in a constrained range of locations. Alternatively, the same events presented as completed tend to highlight information that is typically more associated with resultant states (e.g., participants and objects).

Similar to previous sentence-completion tasks, subject-verb combinations varied considerably not only in the types of phrases that tended to follow them but also in how aspectual morphemes influenced each phrase type. Of the 112 subject-verb combinations, 38 had an overall bias to be followed by a locative prepositional phrase (e.g., The diver was snorkeling in the ocean; see Appendix B), whereas the remainder (74) had an overall bias to be followed by other types of phrases, such as noun phrases (The maid was vacuuming the house) and adverbial phrases (The actress was singing loudly). Furthermore, the imperfective and perfect forms had a differential impact on the types of phrases people produced to specific subject-verb combinations. For example, the subject-verb combination (clown-perform) had an overall bias to be followed by a locative prepositional phrase, but this bias varied considerably by aspect, with $100 \%$ of the completions following imperfective aspect but only 50\% following perfect aspect being locative. In fact, the bias for locative prepositional phrases to be produced more frequently following imperfective versus perfect aspect was much greater for the 38 verbs that had an overall bias to be followed by locative prepositional phrases (imperfective $=$ $79 \%$, perfect $=63 \%$, difference $=16 \%$ ). In contrast, the difference was only $6 \%$ for the remaining 74 verbs (imperfective $=$ $16 \%$, perfect $=10 \%$ ). This suggests that aspect interacts with specific semantic properties of the verb, rather than having a more general influence on all verbs. This issue is explored in more detail in Experiment 3.

\section{Experiment 3}

ERP methodology was used to examine whether, and if so, when, verb aspect influences the activation and use of location information in sentences during online sentence processing. The sentences were based on the subject-verb combinations from Experiment 2 followed by prepositional phrases denoting locations that were either highly plausible/expected or less plausible/ expected for that event. Events were referenced either as ongoing, via past imperfective aspect (was snorkeling), or as completed, via past perfect aspect (had snorkeled). Verbs were followed by locative prepositional phrases regardless of the most preferred type of phrase (based on the offline norming) so that we could control for both sentence meaning and sentence structure and keep the lexical properties of our phrases identical across different aspectual categories (see Examples 3a-3d).

(3a) The diver was snorkeling in the ocean. (imperfective/high expectancy)

(3b) The diver was snorkeling in the pond. (imperfective/low expectancy)

(3c) The diver had snorkeled in the ocean. (perfect/high expectancy)

(3d) The diver had snorkeled in the pond. (perfect/low expectancy)

\section{Language-Related Potentials of Interest}

\section{$N 400$}

The N400 component is the most commonly used ERP measure of semantic analysis during language processing, and it is generally viewed as an index of semantic expectancies at lexical and message levels given some context (single words, sentence, discourse; Brown, Hagoort, \& Kutas, 2000). The standard N400 finding is that words that are more highly semantically expected given the preceding context are associated with smaller negativity between approximately $300 \mathrm{~ms}$ and $500 \mathrm{~ms}$ post-stimulus onset relative to words that are relatively less semantically expected (Kutas \& Federmeier, 2000; Kutas \& Hillyard, 1980). The N400 tends to be broadly distributed over the scalp (often slightly larger over the right hemisphere), with the largest N400 found at central parietal, posterior temporal, and occipital sites (e.g., Kutas, Van Petten, \& Besson, 1988).

In the present research, the N400 may provide an index of the expectancy for specific locations following verbs that reference their corresponding events as ongoing versus completed. If verb aspect has a nonspecific effect such that any location information is more highly activated following imperfective than perfect verbs, regardless of the expectancy for a specific location, then N400 amplitudes should be smaller for any location following imperfective as opposed to perfect aspect. If, however, only location information specific to the verb (event) is activated, then a smaller N400 following the imperfective aspect would be limited to highly expected locations. Alternatively, if location knowledge is event specific but not modulated by aspect, then we would expect to see smaller N400s to expected locations relative to unexpected locations to the same degree regardless of aspect.

\section{Slow Cortical Waves}

A number of studies have indicated that slow potentials that develop over sentences and clauses are sensitive to the ease with which people integrate words into a sentence representation (King \& Kutas, 1995; Münte, Schiltz, \& Kutas, 1998). For example, King and Kutas (1995) recorded ERPs while people read objectrelative (e.g., The reporter who the senator harshly attacked admitted the error) and subject-relative clauses (e.g., The reporter who harshly attacked the senator admitted the error). Objectrelative clauses in English are known to be more difficult to comprehend because the object of the relative clause is the subject of the main clause, whereas for subject relatives, the initial noun is the subject of both clauses (among other reasons). A frontally 
distributed negative slow potential spanning the clauses was larger for object-relative clauses. Furthermore, this negative difference between object- and subject-relative clauses was largest at points in the sentence at which integration would be expected to be most difficult (e.g., at the main verb, admitted). Researchers also have utilized ERP averages that span sentences and clauses to investigate factors that influence the maintenance of verbal information in working memory during filler-gap constructions (e.g., Haarmann, Cameron, \& Ruchkin, 2003) and other forms of syntactic ambiguity resolution (e.g., Bornkessel, Fiebach, \& Friederici, 2004).

Greater slow negativities presumably indexing increased working memory load were also observed by Münte et al. (1998) when comparing biclausal structures that differed only in the first word, a temporal connective (After/Before the scientist submitted the paper, the journal changed its policy). Specifically, they found that Before sentences with reversed chronological order were associated with slow negative potentials over left anterior regions of the scalp, reminiscent of those seen with object-relative sentences. Moreover, the size of this negative difference between the two sentence types was directly modulated by a participant's working memory capacity. Münte et al. concluded that After sentences make fewer demands on working memory because people's world knowledge of the sequential nature of events is more consistent with the temporal reference of sentence-initial After than Before.

Similarly, we expect that manipulating grammatical morphemes that are known to index temporal relations may influence the ease with which people integrate subsequent information into a sentence representation, and thus will be reflected in the coincident slow potentials. Specifically, to the extent that verb aspect modulates the integration of locative prepositional phrases, we expect to see a greater sustained negativity for prepositional phrases following perfect verbs than for those following imperfective verbs.

\section{Method}

\section{Participants}

One hundred forty-eight students received course credit for participating. All were native-English-speaking psychology undergraduates from the University of California, San Diego, who had normal or corrected-tonormal visual acuity. Forty participated in the location generation norms described below, 80 in the preposition generation norms, and 28 in the main experiment.

\section{Materials}

To construct the 112 sentences used in the online experiment, we conducted additional norming studies designed to provide information about the common locations for the events used in Experiment 2 and to determine the prepositions that people expect to be paired with these particular locations.

Location generation norms. Participants were provided with a booklet that contained the nouns and verbs from the 112 sentence fragments in Experiment 2. All verbs were presented in infinitival form, because infinitives do not reference tense and aspect, and were paired with a noun that is a common agent of the event denoted by the verb (e.g., noun: salmon, verb: to migrate). There were two versions of the booklet; one contained the 112 items in a forward order and the second contained the same items in reverse order. The instructions were as follows:
In this experiment, you will be given the name of an entity and an action that it commonly performs. You are asked to write down the locations where those actions commonly occur. We ask that you write down as many places as you can think of in 1 minute; 10 slots have been provided for each item.

Responses were scored on the basis of their rank order within a participant and on their response frequency. That is, each response was scored in terms of the number of participants listing it first, second, third, through to tenth. A weighted score (maximum of 400) was calculated for each response by multiplying the frequency with which it was produced first times 10 , second times 9 , and so on, and then summing these products. We further describe how the locations were selected following the description of how we selected the prepositions.

Preposition generation norms. The aim of this task was to index people's preferences for particular prepositions to be paired with the locations selected from the location generation norms. For each of the 112 subject-verb combinations in Experiment 2, we selected 5-12 locations that varied in location expectancy scores. In the booklets, each item consisted of a blank space between the initial subject-verb combination and the location, which ended the sentence (e.g., $4 \mathrm{a}-4 \mathrm{~b}$ ).

(4a) The diver was snorkeling ocean.

(4b) The cow had grazed field.

In total, there were 1,055 different scenario-location combinations, which we considered to be too many for participants to complete in a single session. Therefore, we divided the locations for each of the 112 scenarios into two lists. We then created two versions of each list whereby each item appeared with past imperfective and past perfect aspect across the two versions. Each specific scenario-location combination was presented to 40 participants.

Construction of sentences for Experiment 3. The first step in finalizing the sentences was to select location and preposition pairs that were highly expected as established by the norming studies. The less expected location condition was constructed by re-pairing the locations and their corresponding prepositional phrases in the sentences that had highly expected locations. In all cases, the locations were re-paired with sentences that had the same type of prepositional phrase preference. Moreover, an effort was made to re-pair locations with events for which they had been listed in the location generation norms as plausible but infrequent (e.g., The diver was snorkeling in the pond). This manipulation ensured that less expected locations were usually at least plausible for the particular events. To constrain our items in this way, we sometimes had to choose a highly expected location that did not have the highest weighted score for a particular event, and in a few other cases, the locations in the less expected condition were not listed for the particular subject-verb combination in the location generation norms. In the unrelated cases in which locations were not listed in the location norms, we again tried to make sure that the locations were at least plausible. However, as a result of the constraint that locations were always re-paired with sentences with the same prepositional phrase preference (which we considered crucial), we were forced to pair a few items with unrelated locations that were implausible. Overall, the mean weighted expectancy score for the highly expected locations $(M=265$, $S E=8)$ was significantly greater than for the low-expectancy locations $(M=28, S E=4), t_{2}(111)=26.03, p<.001$.

The 112 sentences were then placed in four lists with the constraint that each subject-verb combination appeared only once in each list, and across the four lists each combination appeared in both past imperfective and past perfect form and appeared with both a highly and less expected location. Finally, 224 filler sentences were created that consisted of 112 fillers that were in their simple past tense form, 56 fillers that had past imperfective verbs, and 56 fillers with past perfect verbs. The fillers varied in sentence structure, with none having the same structure as our target sentences.

ERP procedure. We began each session by having participants complete a handedness questionnaire to ensure that all participants were right- 
handed. Participants were then tested in a soundproof, electrically shielded chamber while sitting in a chair located approximately $60 \mathrm{~cm}$ in front of a computer monitor. They were instructed to read the words one at a time and to answer periodically presented comprehension questions by pressing buttons labeled Yes and No. The 112 experimental sentences and 224 filler sentences were presented one word at a time in the center of a computer screen. Sentence nonfinal words were presented for a duration of $300 \mathrm{~ms}$ with an SOA of $500 \mathrm{~ms}$. Sentence final words were presented with a duration of $400 \mathrm{~ms}$. The final word was always followed by $3,500 \mathrm{~ms}$ of blank screen. The entire reading task took approximately $1.5 \mathrm{hr}$ to complete.

Electroencephalogram (EEG) recording and analysis. The EEG was recorded from 26 electrodes distributed evenly over the scalp, referenced to the left mastoid. Eye movements and blinks were monitored via electrodes placed on the outer canthus and infraorbital ridge of each eye. Electrode impedances were kept below $5 \mathrm{~K} \Omega$. EEG was processed through Grass amplifiers with a bandpass of $0.01-100 \mathrm{~Hz}$ and was digitized at $250 \mathrm{~Hz}$.

\section{Results}

Data were re-referenced offline to the average of the right and left mastoids. ERP averages were computed in two ways: (a) single word averages with epochs that extended from $100 \mathrm{~ms}$ before the onset of the sentence final word (i.e., the location) to $920 \mathrm{~ms}$ after sentence onset and (b) over-sentence averages with epochs that extended from $200 \mathrm{~ms}$ before the first word of the sentence (The) to $1,000 \mathrm{~ms}$ after the onset of the sentence final word (i.e., -200 to 4,000 ms). Trials contaminated by blinks, eye movements, excessive muscle activity, or amplifier blocking were rejected offline before averaging; $13 \%$ of the trials were lost owing to such artifacts in the single word analysis, and $22 \%$ of the trials were lost in the over-sentence analysis. The analyses reported below were performed on the raw data without any additional filtering.

\section{Single Word Averages to Sentence Final Locations}

On the basis of the literature and visual inspection of the data, the N400 to the location nouns was measured between $300 \mathrm{~ms}$ and $500 \mathrm{~ms}$ following stimulus onset (a 200-ms window around the N400 peak). Time windows of $0-100 \mathrm{~ms}, 100-150 \mathrm{~ms}$, and 150-250 ms were also chosen to investigate the early sensory ERPs (P1, N1, and P2 components, respectively). Mean amplitudes for each participant were subjected to an analysis of variance with repeated measures on two levels of aspect (imperfective vs. perfect), two levels of expectancy (high vs. low), and 26 levels of electrode site. All $p$ values in this and subsequent analyses are reported after epsilon correction (Huynh-Feldt) for repeated measures with greater than two degrees of freedom.

Figure 2 shows the grand average $(n=28)$ for the four experimental conditions at all 26 electrode sites, and Figure 3 highlights the same data for selected electrode sites for the two verb aspects. Table 3 shows the results of the analyses of variance for each component.

N400 analysis (300-500 ms). Expectancy and aspect interacted, $F_{1}(1,24)=5.81, p<.03 ; F_{2}(1,108)=3.39, p<.07$. Planned comparisons revealed that for imperfective aspect, the mean amplitude for the low-expectancy condition $(-0.17$ microvolts $[\mu \mathrm{V}])$ was significantly more negative than for the highexpectancy condition $(1.28 \mu \mathrm{V}), F_{1}(1,24)=13.86, p<.01 ; F_{2}(1$, $108)=15.07, p<.001$. By contrast, for perfect aspect, the difference in mean amplitude for sentences with high- $(0.70 \mu \mathrm{V})$ versus low-expectancy locations $(0.58 \mu \mathrm{V})$ was nonsignificant, $F_{1}<1, F_{2}(1,108)=1.64, p>.20$.

There was no main effect of aspect (both $F \mathrm{~s}<1$ ). The N400 was smaller by approximately $0.79 \mu \mathrm{V}$ for low- $(M=0.20 \mu \mathrm{V})$ than for high-expectancy locations $(M=0.99 \mu \mathrm{V}), F_{1}(1,24)=$ 4.93, $p<.04 ; F_{2}(1,108)=12.98, p<.001$, and this effect interacted with electrode site, $F_{1}(25,600)=2.49, p<.05 ; F_{2}(25$, $2700)=3.22, p<.02$. Finally, the three-way interaction among electrode site, aspect, and expectancy was nonsignificant, $F_{1}(25$, $600)=1.75, p>.09 ; F_{2}(25,2700)=1.29, p>.27$.

$P 1$ analysis $(0-100 \mathrm{~ms})$. Expectancy and aspect interacted, $F_{1}(1,24)=10.53, p<.01 ; F_{2}(1,108)=5.62, p<.02$. Planned comparisons revealed that for perfect aspect, the mean amplitude for the low-expectancy condition $(0.74 \mu \mathrm{V})$ was significantly more positive than for the high-expectancy condition $(0.09 \mu \mathrm{V}), F_{1}(1$, $24)=11.79, p<.01 ; F_{2}(1,108)=2.94, p<.09$. By contrast, for imperfective aspect, the difference was nonsignificant (high = $0.80 \mu \mathrm{V}$, low $=0.58 \mu \mathrm{V}$; both $\left.F_{\mathrm{S}}<1.34\right)$. There was no main effect of expectancy (both $F \mathrm{~s}<1.39$ ). There was a main effect of aspect in the item analysis, with imperfective aspect $(0.61 \mu \mathrm{V})$ producing a $\mathrm{P} 1$ that was more positive than for perfect aspect $(0.22$ $\mu \mathrm{V}), F_{1}(1,24)=1.55, p>.22 ; F_{2}(1,108)=5.62, p<.05$. This effect did not interact with electrode site (both $F \mathrm{~s}<1$ ). The three-way interaction among electrode site, aspect, and expectancy was not reliable (both $F$ s $<1.68$ ).

N100 analysis $(100-150 \mathrm{~ms})$. All effects were nonsignificant.

$P 2$ analysis $(150-250 \mathrm{~ms})$. There was no main effect of expectancy (both $F \mathrm{~s}<1.66$ ). There was a significant main effect of aspect in the item analysis, with imperfective aspect producing a larger P2 than perfect aspect (imperfective $=3.35 \mu \mathrm{V}$, perfect $=$ $2.87 \mu \mathrm{V}), F_{1}<1.01, F_{2}(1,108)=4.02, p<.05$. This effect did not interact with electrode site (both $F \mathrm{~s}<1$ ). This main effect, however, was modified by a marginal interaction between aspect and expectancy, $F_{1}(1,24)=3.91, p<.06 ; F_{2}(1,108)=3.70, p<$ .06. Planned comparisons revealed that for perfect aspect, the mean amplitude for the low-expectancy locations $(3.66 \mu \mathrm{V})$ was more positive than for the high-expectancy locations $(2.60 \mu \mathrm{V})$, $F_{1}(1,24)=5.21, p<.04 ; F_{2}(1,108)=1.81, p>.18$. By contrast, the difference in mean amplitude for imperfective sentences with high- $(3.59 \mu \mathrm{V})$ versus low-expectancy locations $(3.36 \mu \mathrm{V})$ was nonsignificant (both $F \mathrm{~s}<1.89$ ). The three-way interaction among electrode site, aspect, and expectancy was nonsignificant (both $\left.F_{\mathrm{S}}<1.20\right)$.

\section{Over-Sentence Averages Investigating Locative Prepositional Phrase Preferences}

We analyzed the slow potentials starting at the prepositional phrase and extending through to $1,000 \mathrm{~ms}$ following the onset of the sentence final word. We conducted analyses on three sets of items: (a) all 112 items, (b) the 38 items that had an overall bias to be followed by locative prepositional phrases, and (c) the remaining 74 items that were biased to be followed by other types of phrases. Recall that the sentence completions reported in Experiment 2 indicated that for the 38 items with locative prepositional phrase biases, participants generated considerably more of these phrases for verbs marked with imperfective than perfect aspect as compared with the remaining 74 items that were biased to be followed by other types of phrases. On the basis of these comple- 


\section{SENTENCE FINAL LOCATION NOUN}

HE
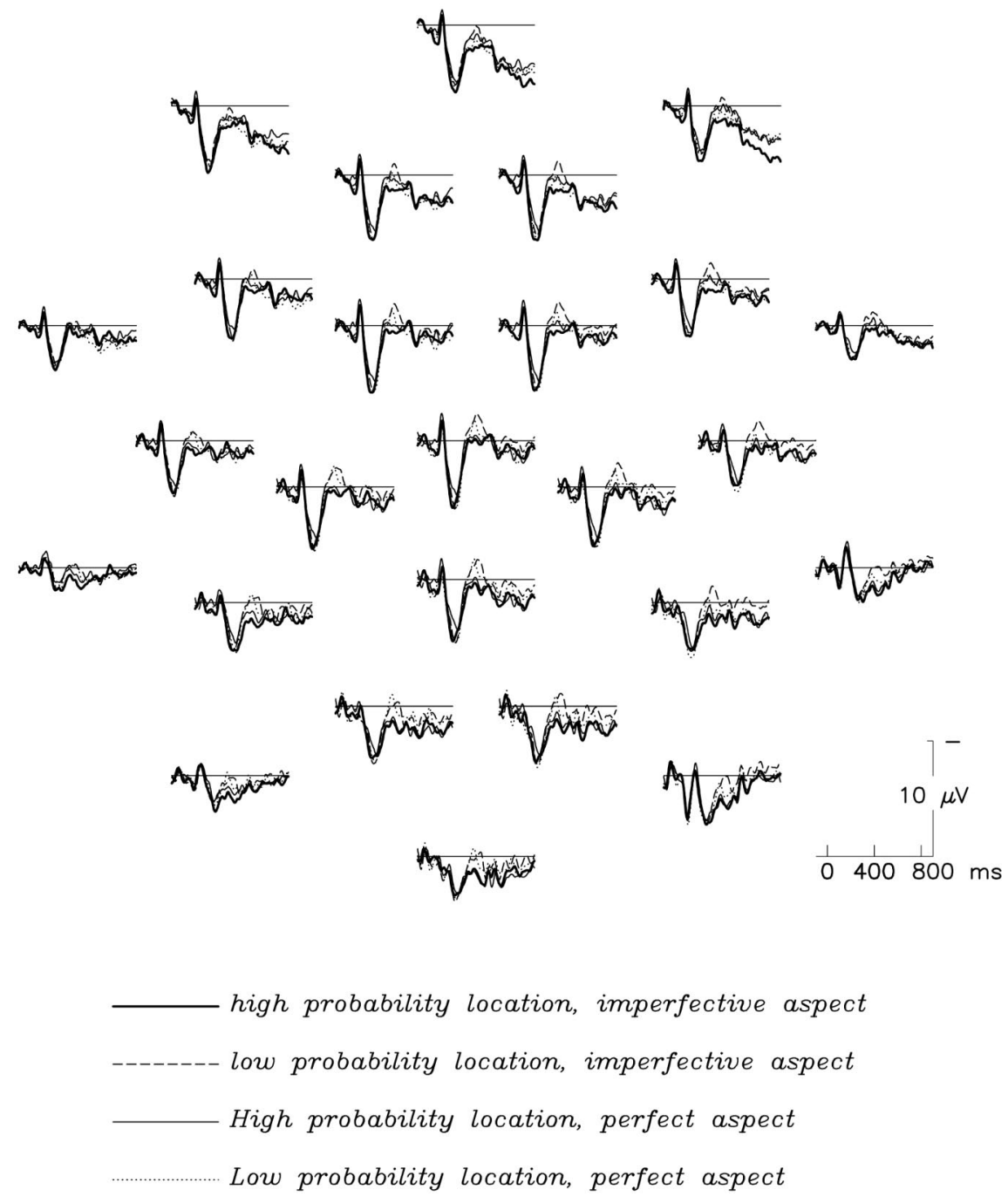

Figure 2. Experiment 3 grand averages $(n=28)$ for the four experimental conditions at all 26 electrode sites. Refer to Figure 1 in Federmeier and Kutas (1999) for a schematic of the electrode cap array used in the present experiment. $\mathrm{HE}=$ horizontal eye electrode.

tion results, we predicted that people would integrate postverbal locative prepositional phrases more easily following imperfective aspect than following perfect aspect for the 38 sentences with verbs biased for locative prepositional phrases. Alternatively, we did not predict a main effect of aspect for the remaining 74 phrases or for all 112 items. Figure 4 shows the slow potentials for the items with verbs biased for locative prepositional phrases.

All items. There was no influence of aspect on prepositional phrase expectancy (both $F_{\mathrm{s}}<1$ ). The interaction between electrode site and aspect was not significant (both $F \mathrm{~s}<1$ ). There was a significant effect of electrode site, $F_{1}(25,600)=23.24, p<$ $.001 ; F_{2}(25,2750)=116.38, p<.001$.

Items with locative prepositional phrase biases. As predicted, the mean amplitudes for prepositional phrases were (margin- ally) more negative in the perfect than in the imperfective condition, $F_{1}(1,24)=3.41, p<.08 ; F_{2}(1,36)=3.99, p=.05$. The interaction between aspect and electrode site was not significant (both $F_{\mathrm{S}}<1$ ). There was a significant effect of electrode site, $F_{1}(25,600)=15.79, p<.001 ; F_{2}(25,900)=$ $36.05, p<.001$.

Items with other biases. Although numerically it was the case that participants had more difficulty integrating the prepositional phrases for verbs with imperfective than those with perfect aspect, the difference was not reliable, $F_{1}(1,24)=2.75, p>.10 ; F_{2}(1$, 72) $=1.96, p>.10$. The interaction between aspect and electrode site was not significant, $F_{1}(1,24)=1.25, p>.10 ; F_{2}(25,1800)=$ $1.03, p>.40$. There was a significant effect of electrode site, $F_{1}(25,600)=22.74, p<.001 ; F_{2}(25,1800)=82.22, p<.001$. 


\section{IMPERFECTIVE PERFECT DIFFERENCE ERPS}

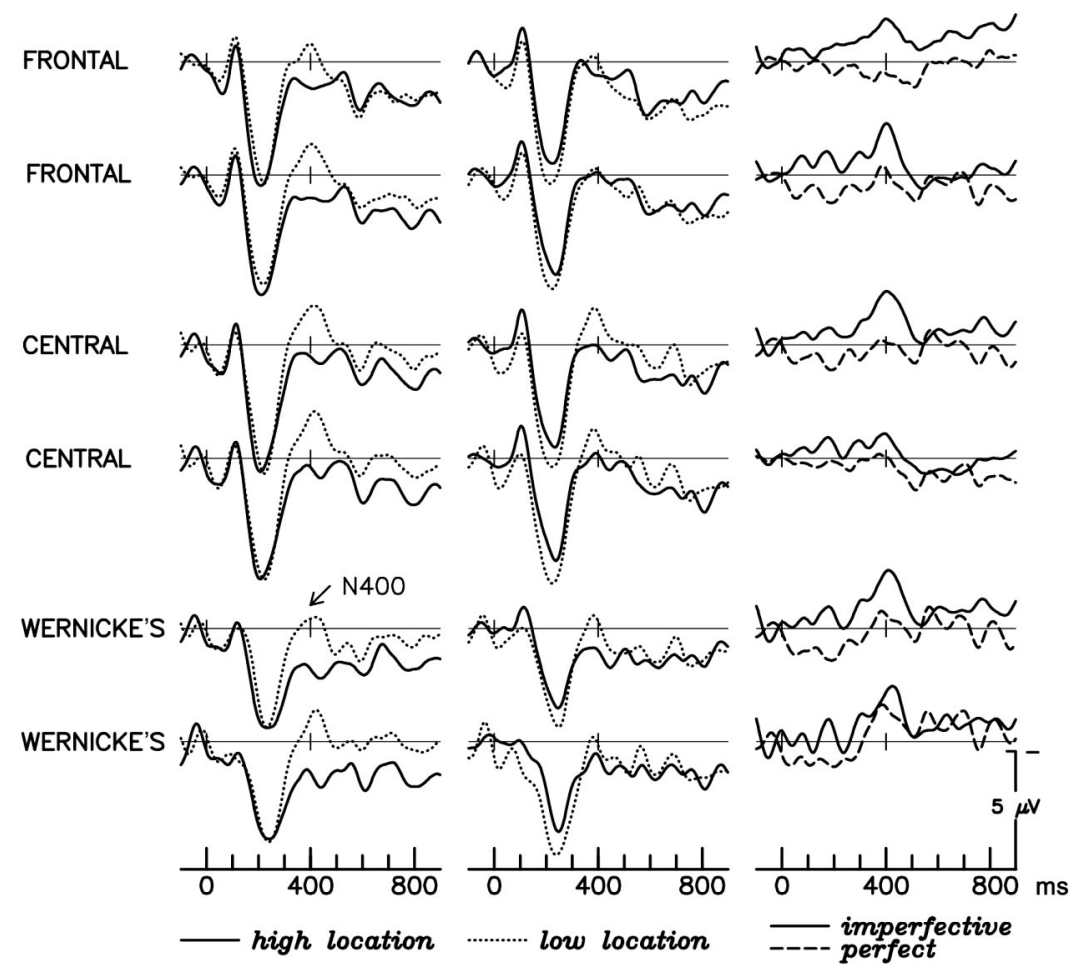

Figure 3. Experiment 3 grand averages $(n=28)$ for the four experimental conditions at frontal (left dorsal frontal, right dorsal frontal), central (left medial central, right medial central), and Wernicke's (left dorsal parietal, right dorsal parietal) electrode sites. Column 1 shows the averages for high- and low-expectancy locations for imperfective aspect, and Column 2 shows the averages for high- and low-expectancy locations for perfect aspect. Column 3 shows the difference waves (high minus low expectancy) for each of the two aspects. ERPS $=$ event-related brain potentials.

\section{Discussion}

In Experiment 3, the N400 amplitudes and over-sentence averages converge to show that people's expectancies for location information during online sentence processing vary as a function of verb aspect. The N400 results show that participants had the highest expectations for and thus had the least difficulty integrating locations when verbs referenced events as ongoing with imperfective aspect and the locations were typical for those events. Alternatively, as reflected in large N400s, participants had the most difficulty integrating locations following the same imperfective verbs when the locations were plausible but not common for the events. N400 amplitudes to the locations following the same events referenced as completed with perfect aspect were intermediate and did not vary significantly as a function of expectancy. This pattern of results suggests that the imperfective form of the verb leads to specific expectations about where the events denoted by the verb will occur, whereas location expectancies are less well formed for sentences in the perfect aspectual form, presumably because locations are less expected in general.

The results of the over-sentence analyses also provide insight into how people integrate location prepositional phrases following imperfective and perfect verbs, and are consistent with the sentence-completion results reported in Experiment 2. Specifically, for verbs that had an overall bias to be followed by locative prepositional phrases, participants had more difficulty integrating the sentences following perfect than imperfective verbs, as reflected in greater over-sentence negativities. In contrast, aspect did not have a significant influence on locative prepositional phrase integration for the verbs that tend to be followed by other types of phrases.

Although unexpected, the ERP data show that even relatively early sensory ERP components in the first $200 \mathrm{~ms}$ following word onset are sensitive to verb aspect. Specifically, the highly typical locations for events denoted by verbs elicited smaller $\mathrm{P} 1 \mathrm{~s}$ and $\mathrm{P} 2 \mathrm{~s}$ when these locations appeared in a prepositional phrase following verbs in the perfect aspect than those to locations in any of the other conditions. This pattern for the early sensory components differed from that observed for the following N400 component and thus cannot readily be explained by resorting to semantic expectancy in combination with ease of semantic integration (Federmeier \& Kutas, 2002; Sereno, Brewer, \& O'Donnell, 2003). These early potentials are known to be sensitive to manipulations of visual processing and visuospatial selective attention. Typically, visual stimuli occur- 
Table 3

Experiment 3 Grand Average $(n=28) N 400, P 1, N 1$, and P2 Results

\begin{tabular}{|c|c|c|}
\hline Effect & $F_{1}$ & $F_{2}$ \\
\hline \multicolumn{3}{|l|}{ N400 (300-500 ms) } \\
\hline Aspect & $F(1,24)<1$ & $F(1,108)<1$ \\
\hline Aspect $\times$ Electrode & $F(25,600)<1$ & $F(25,2700)<1$ \\
\hline Expectancy & $F(1,24)=4.93^{*}$ & $F(1,108)=12.98^{* * *}$ \\
\hline Expectancy $\times$ Electrode & $F(25,600)=2.49^{*}$ & $F(25,2700)=3.22^{*}$ \\
\hline Aspect $\times$ Expectancy & $F(1,24)=5.81^{*}$ & $F(1,108)=3.39^{\dagger}$ \\
\hline Aspect $\times$ Expectancy $\times$ Electrode & $F(25,600)=1.75^{\dagger}$ & $F(25,2700)=1.29$ \\
\hline \multicolumn{3}{|l|}{ P1 $(0-100 \mathrm{~ms})$} \\
\hline Aspect & $F(1,24)=1.55$ & $F(1,108)=5.62^{*}$ \\
\hline Aspect $\times$ Electrode & $F(25,600)<1$ & $F(25,2700)<1$ \\
\hline Expectancy & $F(1,24)=1.39$ & $F(1,108)<1$ \\
\hline Expectancy $\times$ Electrode & $F(25,600)=1.43$ & $F(25,2700)=1.27$ \\
\hline Aspect $\times$ Expectancy & $F(1,24)=10.53^{* *}$ & $F(1,108)=3.95^{*}$ \\
\hline Aspect $\times$ Expectancy $\times$ Electrode & $F(25,600)=1.68$ & $F(25,2700)=1.53$ \\
\hline \multicolumn{3}{|l|}{ N100 $(100-150 \mathrm{~ms})$} \\
\hline Aspect & $F(1,24)<1$ & $F(1,108)<1$ \\
\hline Aspect $\times$ Electrode & $F(25,600)<1$ & $F(25,2700)<1$ \\
\hline Expectancy & $F(1,24)<1$ & $F(1,108)<1$ \\
\hline Expectancy $\times$ Electrode & $F(25,600)=1.53$ & $F(25,2700)=1.86$ \\
\hline Aspect $\times$ Expectancy & $F(1,24)=2.55$ & $F(1,108)=2.66$ \\
\hline Aspect $\times$ Expectancy $\times$ Electrode & $F(25,600)=1.72$ & $F(25,2700)=1.36$ \\
\hline \multicolumn{3}{|l|}{ P2 (150-250 ms) } \\
\hline Aspect & $F(1,24)<1$ & $F(1,108)=4.02^{*}$ \\
\hline Aspect $\times$ Electrode & $F(25,600)<1$ & $F(25,2700)<1$ \\
\hline Expectancy & $F(1,24)=1.66$ & $F(1,108)<1$ \\
\hline Expectancy $\times$ Electrode & $F(25,600)=1.43$ & $F(25,2700)=1.70$ \\
\hline Aspect $\times$ Expectancy & $F(1,24)=3.91^{\dagger}$ & $F(1,108)=3.70^{\dagger}$ \\
\hline Aspect $\times$ Expectancy $\times$ Electrode & $F(25,600)=1.30$ & $F(25,2700)=1.16$ \\
\hline
\end{tabular}

ring in a spatial location that is at the center of attention are associated with larger P1, N1, and P2 components than the same stimuli when they are unattended. The P2 has been linked to visual feature detection and extraction (Luck \& Hillyard, 1994; Scrandies, 2003). Early components also have sometimes been found to vary with lexical variables important for differentiating words from nonwords (Sereno \& Rayner, 2003) and word frequency (Sereno, Rayner, \& Posner, 1998).

At this point, we can only speculate about the pattern of early effects observed. In trial-by-trial visual cuing experiments, in

LOW PASS FILTERED 2Ohz

LOW PASS FILTERED $1 \mathrm{hz}$
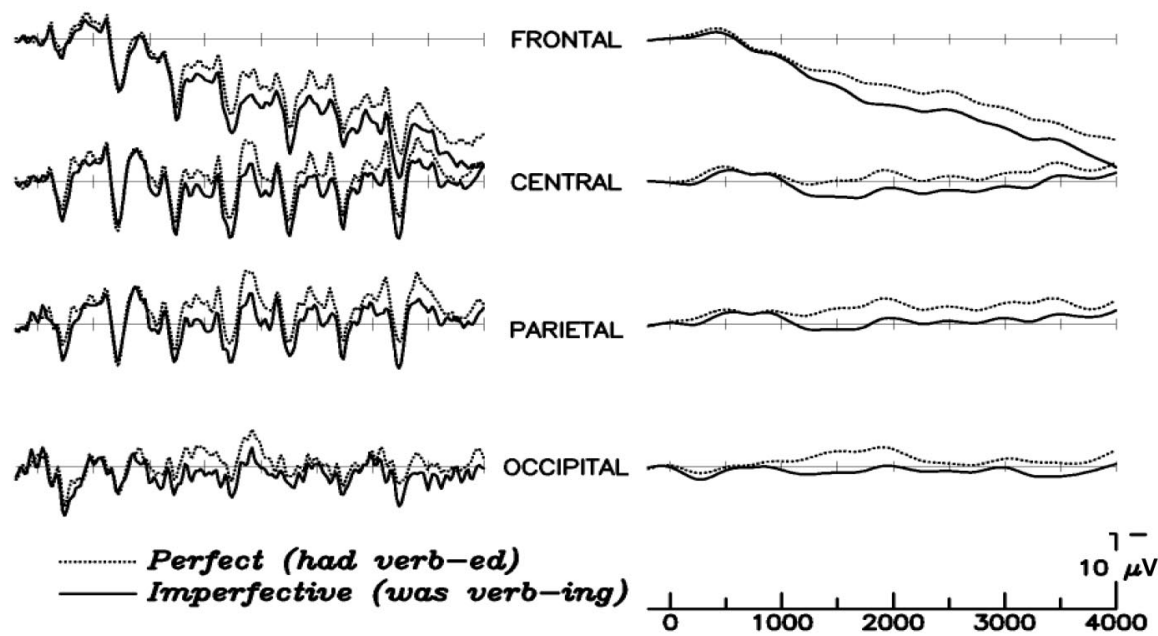

Figure 4. Experiment 3 over-sentence averages for the 38 items that were biased to be followed by locative prepositional phrases at four electrode sites located down the midline of the scalp (mid prefrontal, mid central, mid parietal, mid occipital). 
which a symbolic cue at the start of each trial directs the participant to attend to a particular location, the P1 reliably shows an attention effect: larger P1s to stimuli in the cued (valid) than uncued (invalid) location. However, because the P1 is no larger for uncued (neutral) than for validly cued stimuli, suppressed P1 amplitudes have been taken to reflect the "cost" of shifting attention when it has been misdirected by a cue. On this view, if readers use verb aspect as a symbolic cue to direct fewer, if any, attentional resources to typical location information (e.g., by actively suppressing it) following perfective verbs, the reduced P1 may reflect the mental cost of needing to process location information nonetheless when it is provided by the sentence context. Although further research is needed to clarify whether, and if so, how, verb aspect influences the allocation of visuoattentional resources during sentence processing, the amplitude modulations on these early visual ERP components (but only for highly typical locations following verbs with perfective aspect) demonstrate that remarkably it does.

\section{General Discussion}

The goal of this research was to investigate how people combine morphosyntactic information with event-specific knowledge when interpreting phrases in isolation and in sentences. Experiment 1 demonstrated that locations of specific events are more highly activated when verbs reference situations as ongoing (imperfective aspect) versus completed (perfect aspect). Moreover, given the short SOA used, our results show that verb aspect acts quickly to modulate the activation of world knowledge of events from verbs. The influence of morphosyntactic information falls naturally out of, and its investigation was inspired by, an account that focuses on the influence of event knowledge on language processing. In contrast, these results are problematic for theories of semantic priming based on the notion of spreading activation, as these typically contain no mechanisms that can account for the modulating influence of verb aspect. Although the assumption that the initial spread of activation is constrained by morphosyntactic information could be incorporated into such models, this would significantly alter the spirit of spreading activation models.

The results of Experiments 2 and 3 indicate that the location information that is computed from a verb influences people's expectations for upcoming location information in sentences, including expectations for locative prepositional phrases and for locations that are typical for those events. Thus, this research adds to the considerable body of evidence indicating that syntactic information interacts with people's background knowledge of the world during online sentence processing (Boland, Tanenhaus, Carlson, \& Garnsey, 1989; Ferretti et al., 2001; McRae et al., 1998; Morris, 1994).

A great deal of research, most of which has been conducted by researchers who adhere to constraint-based models of sentence comprehension, has investigated the ways in which verbs drive sentence comprehension (Boland et al., 1989; Garnsey, Pearlmutter, Myers, \& Lotocky, 1997; MacDonald et al., 1994; Trueswell et al., 1994). There is an interesting evolution of this work. Researchers such as Garnsey et al. (1997) found that structural preferences of verbs influence structural expectations (e.g., for a postverbal direct object versus a sentence complement). Preference statistics were considered to be verb specific and were calculated for each verb in the aggregate. Next, Hare, McRae, and Elman (2003, 2004) showed that expectations due to structural biases were contingent on verb sense (e.g., admit in the "let in" sense is direct object biased, whereas in the "acknowledge" sense, it is sentence complement biased). The present research takes constraint-based models one step further; structural (and semantic) expectations for a verb can change depending on aspect. Thus, constraint-based theories are evolving by explicating the roles of types of information that are becoming progressively more fine grained. One implication of this progression is that the relevant knowledge cannot be considered as part of some static lexical entry but must be viewed as more fluid and dynamic and tied to people's online computations of event knowledge.

Although there is no doubt that expectations can be driven by the verb per se, there are further reasons underlying why it is becoming increasingly clear that expectations are not tied strictly to the verb but instead are tied to events more generally. For example, Kamide, Altmann, and Haywood (2003) used headmounted eye-tracking methodology to demonstrate that specific agents, such as girl and man, and verbs, such as ride, interact to modulate expectations for upcoming patients: carousel when the agent is girl, motorbike when the agent is man. McRae, Hare, Elman, and Ferretti (2005) used a short SOA semantic priming paradigm to show that nouns denoting entities and objects (e.g., actor, ball, axe, airport) that play specific roles in events (agent, patient, instrument, location) can produce expectations for verbs that denote those events ( performing, thrown, chopping, flying). In the present research, the verb was the same in the key comparisons between imperfective and perfect aspect, whereas aspect was used to focus comprehenders on relevant event components. Taken together, these findings, like the results on structural biases, suggest that the knowledge underlying language comprehension cannot be captured by information stored in a lexical entry of a verb. Rather, it suggests a dynamic interplay between event knowledge and the linguistic stream.

Finally, our results add to the growing body of research in the discourse-processing literature indicating that verb aspect influences people's construction of situation models (Carreiras et al., 1997; Madden \& Zwaan, 2003; Magliano \& Schleich, 2000). In particular, our research highlights the notion that the content of people's situation models varies according to whether the events in the text are referenced as ongoing or completed. Previous research has shown that the events and their common properties, such as participants and instruments, are more activated in situation models when those events are referenced as ongoing. Our data show that world knowledge concerning the likely locations of those participants is likewise modulated by verb aspect. In the present research, we have proposed an account based on the interplay between aspect and event structure. However, further research may be needed to investigate alternative accounts of our results. One possibility, for example, is that the location bias found with imperfective aspect may result from the more frequent use of imperfective aspect as a setting for subsequently described events. As a result, setting information, such as expected locations, may be more likely to accompany imperfective event descriptions. This would, in essence, be consistent with our account in that because language production (as evidenced by corpora statistics, for example) is influenced by verb aspect, aspect-location contingencies are 
learned through experience, which then influences expectancy generation during online language comprehension.

In conclusion, the research reported herein demonstrates the value of integrating various research areas, including theories of semantic priming, sentence processing, and discourse processing, in combination with both behavioral and neurocognitive methodology. Integrating these areas and methods leads to important insights regarding the processes that underlie language comprehension.

\section{References}

Altmann, G. T. M., \& Kamide, Y. (1999). Incremental interpretation at verbs: Restricting the domain of subsequent reference. Cognition, 73, 247-264.

Boland, J. E., Tanenhaus, M. K., Carlson, G., \& Garnsey, S. M. (1989). Lexical projection and the interaction of syntax and semantics in parsing. Journal of Psycholinguistic Research, 18, 563-576.

Bornkessel, I. D., Fiebach, C. J., \& Friederici, A. D. (2004). On the cost of syntactic ambiguity in human language comprehension: An individual differences approach. Cognitive Brain Research, 21, 11-21.

Brown, C. M., Hagoort, P., \& Kutas, M. (2000). Postlexical integration processes in language comprehension: Evidence from brain-imaging research. In M. S. Gazzaniga (Ed.), The new cognitive neurosciences (pp. 881-898). Cambridge, MA: MIT Press.

Carreiras, M., Carriedo, N., Alonso, M. A., \& Fernandez, A. (1997). The role of verb tense and verb aspect in the foregrounding of information during reading. Memory \& Cognition, 25, 438-446.

Cohen, J. D., MacWhinney, B., Flatt, M., \& Provost, J. (1993). PsyScope: A new graphic interactive environment for designing psychology experiments. Behavior Research Methods, Instruments \& Computers, 25, 257-271.

Collins, A. M., \& Loftus, E. F. (1975). A spreading-activation theory of semantic processing. Psychological Review, 82, 407-428.

Collins, A. M., \& Quillian, M. R. (1969). Retrieval time from semantic memory. Journal of Verbal Learning and Verbal Behavior, 8, 240-247.

Comrie, B. (1976). Aspect: An introduction to the study of verbal aspect and related problems. New York: Cambridge University Press.

Federmeier, K. D., \& Kutas, M. (1999). A rose by any other name: Long-term memory structure and sentence processing. Journal of Memory and Language, 41, 469-495.

Federmeier, K. D., \& Kutas, M. (2002). Picture the difference: Electrophysiological investigations of picture processing in the two cerebral hemispheres. Neuropsychologia, 40, 730-747.

Ferretti, T. R., Gagné, C. L., \& McRae, K. (2003). Thematic role focusing from participle inflections: Evidence from conceptual combination. Journal of Experimental Psychology: Learning, Memory, and Cognition, 29, 118-126.

Ferretti, T. R., McRae, K., \& Hatherell, A. (2001). Integrating verbs, situation schemas, and thematic role concepts. Journal of Memory and Language, 44, 516-547.

Garnsey, S. M., Pearlmutter, N. J., Myers, E., \& Lotocky, M. A. (1997). The contribution of verb-bias and plausibility to the comprehension of temporarily ambiguous sentences. Journal of Memory and Language, 37, 58-93.

Gentner, D. (1975). Evidence for the psychological reality of semantic components: The verbs of possession. In D. A. Norman \& D. E. Rumelhart (Eds.), Explorations in cognition (pp. 211-246). San Francisco: Freeman.

Givón, T. (1992). The grammar of referential coherence as mental processing instructions. Linguistics, 30, 5-55.

Haarmann, H. J., Cameron, K. A., \& Ruchkin, D. S. (2003). Short-term semantic retention during on-line sentence comprehension: Brain poten- tial evidence from filler-gap constructions. Cognitive Brain Research, $15,178-190$.

Hare, M., McRae, K., \& Elman, J. L. (2003). Sense and structure: Meaning as a determinant of verb subcategorization preferences. Journal of Memory and Language, 48, 281-303.

Hare, M., McRae, K., \& Elman, J. L. (2004). Admitting that admitting verb sense into corpus analyses makes sense. Language and Cognitive Processes, 19, 181-224.

Hopper, P. (1982). Aspect between discourse and grammar. In P. Hopper (Ed.), Tense-aspect between semantics and pragmatics (pp. 3-18). Amsterdam: John Benjamins.

Kamide, Y., Altmann, G. T. M., \& Haywood, S. L. (2003). The timecourse of prediction in incremental sentence processing: Evidence from anticipatory eye movements. Journal of Memory and Language, 49, $133-156$.

King, J. W., \& Kutas, M. (1995). Who did what and when? Using word and clausal level ERPs to monitor working memory usage in reading. Journal of Cognitive Neuroscience, 7, 376-395.

Kutas, M., \& Federmeier, K. D. (2000). Electrophysiology reveals semantic memory use in language comprehension. Trends in Cognitive Science, 4, 463-470.

Kutas, M., \& Hillyard, S. A. (1980, January 11). Reading senseless sentences: Brain potentials reflect semantic incongruity. Science, 207, 203-205.

Kutas, M., Van Petten, C., \& Besson, M. (1988). Event-related potential asymmetries during the reading of sentences. Electroencephalography and Clinical Neurophysiology, 69, 218-233.

Langacker, R. W. (1982). Remarks on English aspect. In P. Hopper (Ed.), Tense/aspect: Between semantics and pragmatics (pp. 265-304). Amsterdam: John Benjamins.

Luck, S. J., \& Hillyard, S. A. (1994). Spatial filtering during visual search: Evidence from human electrophysiology. Journal of Experimental Psychology: Human Perception and Performance, 20, 1000-1014.

MacDonald, M. C., Pearlmutter, N. J., \& Seidenberg, M. S. (1994). The lexical nature of syntactic ambiguity resolution. Psychological Review, 101, 676-703.

Madden, C. J., \& Zwaan, R. A. (2003). How does verb aspect constrain event representations? Memory \& Cognition, 31, 663-672.

Magliano, J. P., \& Schleich, M. C. (2000). Verb aspect and situation models. Discourse Processes, 29, 83-112.

McRae, K., Ferretti, T. R., \& Amyote, L. (1997). Thematic roles as verb-specific concepts. Language and Cognitive Processes, 12, 137 176.

McRae, K., Hare, M., Elman, J. L., \& Ferretti, T. R. (2005). A basis for generating expectancies for verbs from nouns. Memory \& Cognition, 33, $1174-1184$.

McRae, K., Spivey-Knowlton, M. J., \& Tanenhaus, M. K. (1998). Modeling the influence of thematic fit (and other constraints) in on-line sentence comprehension. Journal of Memory and Language, 38, 283312 .

Moens, M., \& Steedman, M. J. (1988). Temporal ontology and temporal reference. Computational Linguistics, 14, 15-28.

Morris, R. K. (1994). Lexical and message level sentence context effects on fixation times in reading. Journal of Experimental Psychology: Learning, Memory, and Cognition, 20, 92-103.

Morrow, D. G. (1985). Prepositions and verb aspect in narrative understanding. Journal of Memory and Language, 24, 390-404.

Morrow, D. G. (1990). Spatial models, prepositions, and verb-aspect markers. Discourse Processes, 13, 441-469.

Moss, H. E., Ostrin, R. K., Tyler, L. K., \& Marslen-Wilson, W. D. (1995). Accessing different types of lexical semantic information: Evidence from priming. Journal of Experimental Psychology: Learning, Memory, and Cognition, 21, 863-883.

Münte, T. F., Schiltz, K., \& Kutas, M. (1998, September 3). When 
temporal terms belie conceptual order: An electrophysiological analysis. Nature, 395, 71-73.

Neely, J. H. (1991). Semantic priming effects in visual word recognition: A selective view of current findings and theories. In D. Besner \& G. Humphreys (Eds.), Basic processes in reading: Visual word recognition (pp. 264-336). Hillsdale, NJ: Erlbaum.

Nelson, D. L., McEvoy, C. L., \& Pointer, L. (2003). Spreading activation or spooky action at a distance. Journal of Experimental Psychology: Learning, Memory, and Cognition, 29, 42-52.

Pollatsek, A., \& Well, A. D. (1995). On the use of counterbalanced designs in cognitive research: A suggestion for a better and more powerful analysis. Journal of Experimental Psychology: Learning, Memory, and Cognition, 21, 785-794.

Rumelhart, D. E., \& Levin, A. (1975). A language comprehension system. In D. A. Norman \& D. E. Rumelhart (Eds.), Explorations in cognition (pp. 179-208). San Francisco: Freeman.

Scrandies, W. (2003). Evoked potentials studies of visual information processing. In A. Zani \& A. Proverbio (Eds.), The cognitive electrophysiology of mind and brain (pp. 71-92). New York: Academic Press. Sereno, S. C., Brewer, C. C., \& O'Donnell, P. J. (2003). Context effects in word recognition: Evidence for early interactive processing. Psychological Science, 14, 328-333.

Sereno, S. C., \& Rayner, K. (2003). Measuring word recognition in reading: Eye movements and event-related potentials. Trends in Cognitive Sciences, 7, 489-493.

Sereno, S. C., Rayner, K., \& Posner, M. (1998). Establishing a time-line of word recognition: Evidence from eye movements and event-related potentials. NeuroReport: An International Journal for the Rapid Communication of Research in Neuroscience, 9, 2195-2200.

Shelton, J. R., \& Martin, R. C. (1992). How semantic is automatic semantic priming? Journal of Experimental Psychology: Learning, Memory, and Cognition, 18, 1191-1210.

Smith, C. S. (1991). The parameter of aspect. Boston: Kluwer Academic. Trueswell, J. C., Tanenhaus, M. K., \& Garnsey, S. M. (1994). Semantic influences on parsing: Use of thematic role information in syntactic ambiguity resolution. Journal of Memory and Language, 33, 285319.

Truitt, T. P., \& Zwaan, R. A. (1997, November). Verb aspect affects the generation of instrumental inferences. Paper presented at the 38th Annual Meeting of the Psychonomic Society, Philadelphia.

\section{Appendix A}

Experiment 1 Related Verb-Location Pairs With Their Ratings

\begin{tabular}{llcl}
\hline Related verb & Location & Rating & Unrelated verb \\
\hline cook & kitchen & 7.0 & worship \\
exercise & gymnasium & 7.0 & mourn \\
drive (had driven) & highway & 7.0 & pray \\
skate & arena & 7.0 & browse \\
sleep (had slept) & bedroom & 7.0 & devour \\
dance & ballroom & 7.0 & sleep \\
eat (had eaten) & restaurant & 7.0 & study \\
hunt & forest & 6.9 & bury \\
act & theater & 6.9 & skate \\
study & library & 6.9 & draw \\
shower & bathroom & 6.9 & swim \\
gamble & racetrack & 6.8 & drive \\
pray & temple & 6.8 & act \\
mourn & cemetery & 6.8 & confess \\
stroll & park & 6.8 & exercise \\
preach & synagogue & 6.7 & trawl \\
applaud & stadium & 6.7 & stroll \\
worship & chapel & 6.7 & cook \\
browse & museum & 6.6 & bet \\
swim (had swam) & ocean & 6.6 & shower \\
draw (had drawn) & studio & 6.5 & applaud \\
bury & sandbox & 6.3 & track \\
fish & river & 6.2 & dance \\
confess & court & 6.0 & \\
\hline
\end{tabular}

Note. Verbs appeared in both their past imperfective form (was verb-ing) and their past perfect form (had verb-ed). Irregular past participle forms are indicated in parentheses. 


\section{Appendix B}

\section{Items in Experiment 3 Biased to Be Followed by a Locative Prepositional Phrase}

Note that the high- and low-expectancy locations for each sentence are shown in brackets.

The girl was skating in the [rink/ring].

The prostitute was walking down the [street/slope].

The commuter was parking in the [parking-lot/space].

The boy was tobogganing down the [hill/street].

The king was sitting on the [throne/stage].

The rat was scurrying across the [floor/border].

The weightlifter was exercising at the [gym/beach].

The snake was slithering in the [desert/hole].

The horse was residing in the [stable/grass].

The cow was grazing in the [field/stable].

The turkey was roasting in the [oven/kitchen].

The golfer was slipping on the [green/throne].

The crocodile was crawling in the [swamp/woods].

The scout was camping in the [woods/cavern].

The fireman was resting at the [station/bank].

The boy was hiking up the [mountain/stream].

The woman was strolling in the [park/lot].

The goaltender was falling on the [field/stage].

The frog was hopping on the [lily-pad/ship].

The girl was hiding in the [closet/field].
The boy was skiing down the [slope/hill]. The pilot was flying in the [sky/ocean].

The bear was hibernating in the [cave/tree].

The diver was snorkeling in the [ocean/pond].

The cricket was jumping in the [grass/closet].

The boy was fishing in the [lake/swamp].

The woman was tanning in the [backyard/web].

The monkey was swinging in the [jungle/forest].

The tourist was browsing in the [shop/park].

The chef was cooking in the [kitchen/oven].

The pitcher was standing on the [mound/deck].

The girl was swimming in the [pool/backyard].

The diplomats were meeting at the [White House/conference].

The girl was showering in the [bathroom/lake].

The sailor was napping on the [deck/lily-pad].

The duck was floating in the [pond/bath].

The family was parting at the [airport/funeral].

The man was sailing across the [ocean/floor].

Received February 6, 2006

Revision received July 6, 2006

Accepted July 11, 2006 